\title{
National survey of blindness and low vision in Lebanon
}

A M Mansour, Kassem Kassak, Monique Chaya, Talal Hourani, Abla Sibai, M N Alameddine

\begin{abstract}
Aims-To survey level of blindness and low vision in Lebanon. Methods-A population survey was undertaken in 10148 individuals to measure the prevalence and identify the causes of blindness in Lebanon.

Results-The prevalence of blindness was $0.6 \%$ and that of low vision $3.9 \%$. The major causes of blindness were cataract $(41.3 \%)$ and uncorrected large refractive error $(12.6 \%)$.

Conclusion-Most causes of blindness in Lebanon can be controlled by various educational and medical programmes.

(Br f Ophthalmol 1997;81:905-906)
\end{abstract}

Forty million people are estimated to be blind worldwide. ${ }^{12}$ There are no available data on the number of blind in Lebanon. A national survey was undertaken to estimate the prevalence and causes of blindness and low vision.

\section{Materials and methods}

Based on WHO reports of $2.5 \%$ prevalence of low vision rates for the eastern Mediterranean region in $1988,{ }^{12}$ it is appropriate to estimate that for Lebanon in 1995 this rate would be around $2 \%$. At $95 \%$ confidence interval a minimum sample to represent the population was estimated at 10000 individuals or the equivalent of 2000 households. To account for attrition, $25 \%$ was added to the original estimate yielding a required sample of 2500 households. These were proportionately sampled by districts. Within each district, a cluster of regions was randomly selected to represent the district. Using the cumulative total method in probability proportional to sample size sampling, villages were selected. Households were selected randomly based on a quick mapping by the investigating team and a systematic random sampling approach.

According to this multistage cluster sampling scheme, 2568 households (11 218 subjects) were selected. A group of 324 subjects $(2.9 \%)$ refused to participate, and 746 subjects $(6.6 \%)$ were absent from the household. A total of 10148 individuals (4742 males and 5406 females) participated in the survey having a mean age of 29 years (range 3-98). Data were collected using the WHO Eye Examination Record. ${ }^{1}$ Trained field interviewers filled in the information relating to census, previous eye surgery, and visual acuity using standardised Snellen E charts with and without pinhole. The causes of blindness were filled in by the ophthalmologist. Blind subjects (low vision patients excluded) were referred to an ophthalmologist for a comprehensive ocular examination. Blindness was defined as a visual acuity of less than 0.05 or $3 / 60$ in the better eye, and low vision as a visual acuity less than 0.3 or $6 / 18$ but equal or better than 0.05 or $3 / 60$ in the better eye. ${ }^{2}$ Visual field screening was not performed by the interviewers.

\section{Results}

Except for minor differences, the sample was similar to the general population surveyed by the Ministry of Social Affairs (Ministry of Social Affairs: Population Survey, 1994-1996). The prevalence of blindness was $0.6 \%$ and low vision $3.9 \%$ (confidence interval at $95 \%=$ 0.0015 ) (Tables 1 and 2). The prevalence of blindness was similar for both sexes, increased with age, and increased for the rural group compared with the urban group. No ruralurban differences were found in age specific rates of subjects under 50 years of age. The rural-urban prevalence of blindness ratio was fourfold in the age group 50-64, and eightfold in subjects above 64 years of age. The causes of blindness included cataract $(41.3 \%)$, refractive error such as high myopia or hyperopia or astigmatism or uncorrected aphakia (12.6\%), non-trachomatous corneal opacities $(7.5 \%)$, optic atrophy $(7.5 \%)$, disorganised globes by trauma $(5.0 \%)$, macular degeneration $(3.8 \%)$, diabetic retinopathy $(2.5 \%)$, and glaucoma $(2.5 \%)$. There were no cases of xerophthalmia, measles keratitis, onchocerciasis, or trachomatous corneal scar causing blindness. The proportion of cataract among blind people was double in the rural regions than in the urban regions. Ninety per cent of blind (bilaterally)

Table 1 Prevalence of blindness and low vision in Lebanon by sex, 1995

\begin{tabular}{llllll}
\hline & \multicolumn{2}{c}{ Blindness } & & \multicolumn{2}{c}{ Low vision } \\
\cline { 2 - 3 } \cline { 5 - 6 } & Bilateral & Unilateral & & Bilateral & Unilateral \\
\hline Male & $0.5 \%$ & $1.6 \%$ & & $3.2 \%$ & $3.3 \%$ \\
Female & $0.6 \%$ & $1.3 \%$ & & $4.6 \%$ & $4.0 \%$ \\
Total & $0.6 \%$ & $1.5 \%$ & & $3.9 \%$ & $3.7 \%$ \\
\hline
\end{tabular}

Table 2 Prevalence of blindness and low vision in Table 2 Prevalence of
Lebanon by age, 1995

\begin{tabular}{clllll}
\hline & \multicolumn{2}{l}{ Blindness } & & \multicolumn{2}{c}{ Low vision } \\
\cline { 2 - 3 } \cline { 5 - 6 } Age group & Unilateral & Bilateral & & Unilateral & Bilateral \\
\hline $3-14$ & $0.3 \%$ & $0.1 \%$ & & $1.5 \%$ & $1.1 \%$ \\
$15-29$ & $0.7 \%$ & $0.1 \%$ & & $2.1 \%$ & $1.5 \%$ \\
$30-44$ & $1.2 \%$ & $0.2 \%$ & & $3.7 \%$ & $2.4 \%$ \\
$45-59$ & $2.0 \%$ & $7.0 \%$ & & $7.7 \%$ & $6.9 \%$ \\
$60+$ & $7.3 \%$ & $4.3 \%$ & & $10.2 \%$ & $18.6 \%$ \\
Total & $1.5 \%$ & $0.6 \%$ & & $3.7 \%$ & $3.9 \%$ \\
\hline
\end{tabular}

Accepted for publication 1 May 1997 
subjects were unemployed, with the younger age groups being more likely to be employed than the older age groups. More than half of the blind were married (59\%), and illiteracy was more common in the older age groups (60\% in the age group $40-49$ versus $33 \%$ in the age group 20-29).

The prevalence of low vision was similar for both sexes and increased with age (Tables 1 and 2). Subjects who were not able to see $6 / 18$ were further asked to read the Snellen chart using a pinhole. Approximately $50 \%$ of these people had their vision improved to $6 / 18$ or better with the pinhole. Moreover, $12 \%$ of the total subjects surveyed wore glasses.

\section{Discussion}

Based on an a recent demographic survey (Ministry of Social Affairs: Population Survey 1994-1996) and on age specific prevalences of blindness correcting for children below age 3 years, the expected number of blind people in Lebanon is 17898 and that of low vision people 100 158. Blindness in Lebanon is similar in number and age to the global blindness in the world and to the rest of the Mediterranean countries (Tables 3 and 4). Like in other developing countries (Table 4), cataract constitutes the main cause of blindness. Cataract appears more prevalent in the rural population than in the urban population. This rural-urban difference can be partly attributed to exposure to sunlight in the rural fields-knowing that ultraviolet light is cataractogenic ${ }^{34}$ and that Lebanon has around 2000 hours of sunlight yearly. The backlog of unoperated cataracts in Lebanon is not due to lack of cataract surgeons (Lebanon has modern eye surgical facilities including American, French, and German hospitals) or for economic reasons (cataract surgery is free for needy subjects) but rather the result of the level of education and the strong belief among Lebanese senior citizens that surgery for cataract should be delayed till the cataract is fully mature.

A high percentage of Lebanese people are smokers and this may contribute to an increased prevalence of cataract in the Lebanese community. ${ }^{56} \mathrm{~A}$ peculiar problem in Lebanon is refusal of a large section of the population to wear glasses because glasses are viewed as 'stigmata of blindness', and single women have less chance of getting married if they wear glasses. Education, contact lens wear, or refractive surgery may help this latter group of people reluctant to wear glasses. In this study, ocular trauma was a more important cause of blindness than macular degeneration,
Table 3 Prevalence of blindness and low vision by age in Lebanon compared with world blindness data derived from Thylefors ${ }^{2}$

\begin{tabular}{clcl}
\hline Age (years) & $\begin{array}{l}\text { Blindness } \\
\text { (Lebanon) }\end{array}$ & $\begin{array}{l}\text { Low vision } \\
\text { (Lebanon) }\end{array}$ & $\begin{array}{l}\text { WHO global } \\
\text { blindness }^{2}\end{array}$ \\
\hline $3-14$ & $0.1 \%$ & $1.1 \%$ & $0.1 \%$ \\
$15-29$ & $0.1 \%$ & $1.5 \%$ & $0.1 \%$ \\
$30-44$ & $0.2 \%$ & $2.4 \%$ & $0.1 \%$ \\
$45-59$ & $0.7 \%$ & $6.9 \%$ & $1.9 \%$ \\
$60+$ & $4.3 \%$ & $18.6 \%$ & $4.4 \%$ \\
Total & $0.6 \%$ & $3.9 \%$ & $0.7 \%$ \\
\hline
\end{tabular}

Table 4 Prevalence of blindness by economic region and percentage of blindness from cataract (data extracted from Thylefors ${ }^{2}$ )

\begin{tabular}{lll}
\hline & $\begin{array}{l}\text { Prevalence of blindness } \\
\text { by economic region (\%) }\end{array}$ & $\begin{array}{l}\text { Cataract as \% of } \\
\text { blindness }\end{array}$ \\
\hline $\begin{array}{l}\text { Established } \\
\text { market }\end{array}$ & & \\
$\quad$ economies & 0.3 & \\
$\begin{array}{l}\text { Former socialist } \\
\quad \text { European }\end{array}$ & & 3.9 \\
$\quad$ economies & 0.3 & \\
Latin America & 0.5 & 5.1 \\
China & 0.6 & 57.7 \\
Lebanon & 0.6 & 32.3 \\
Middle Eastern & & 41.3 \\
$\quad$ crescent & 0.7 & 45.2 \\
India & 1.0 & 57.5 \\
Sub-Saharan & & \\
$\quad$ Africa & 1.4 & 43.7 \\
Total & 0.7 & 41.8 \\
\end{tabular}

diabetic retinopathy, or glaucoma. This may be attributed to various factors-20 years of civil war; a large number of motor vehicle accidents (most cars are not equipped with seat belts or air bags, speed limits are not enforced, and most motorcycle riders do not wear helmets); and poor safety conditions at work like chiselling iron on iron without wearing safety glasses.

This survey sets the stage for future intervention programmes to prevent blindness such as wearing sunglasses or hats, antismoking campaigns, diet and antioxidants, earlier timing of cataract surgery, and wearing protective goggles at work.

1 Thylefors B. The WHO program for the prevention of blindness and cataract in developing countries. Doc Ophthalmol 1992;81:339-44.

2 Thylefors B, Negrel AD, Pararajasegaram R, Dadzie KY. Global data on blindness. Bull WHO 1995;73:115-21.

3 Taylor HR, West SK, Rosenthal FS, Muñoz B, Newland $\mathrm{HS}$, Abbey $\mathrm{H}$, et al. Effect of ultraviolet radiation on cataract formation. N Engl F Med 1988;319:1429-33.

4 Brilliant LB, Grasset NC, Pokhrel RP, Kolstad A, Lepkawski JM, Brilliant GE, et al. Associations among cataract prevance, sunlight hours, and altitude in the Himalayas. prevalence, sunlight hours, and a

5 Christen WG, Manson JE, Seddon JM, Glynn RJ, Buring JE, Rosner B, et al. A prospective study of cigarette smok-
ing $\mathrm{JE}$, Rosner B, et al. A prospective study of cigarette smok-
ing and risk of cataract in men. $¥ A M A 1992 ; 268: 989-93$. ing and risk of cataract in men. $\mathcal{F} A M A$ 1992;268:989-93.
6 Hankinson SE, Willett WC, Colditz GA, Seddon JM, Rosner B, Speizer FE, et al. A prospective study of smoking and risk of cataract in women. $\mathscr{f} A M A$ 1992;268:994-8. 